\title{
Techniques and Practice of Post Mastectomy Radiotherapy in Nigeria: A Multi-Centre Study
}

\author{
Salako Omolola ${ }^{1}$, Aliyu Usman Malami ${ }^{2, ~ *}$, Jimoh Mutiu Alani ${ }^{3}$, Oboh Oseiwe Evaristus ${ }^{4}$, \\ Nwankwo Kenneth $^{5}$, Ogunnorin Babatunde Olutoye ${ }^{2}$, Habeeb Muhammed ${ }^{1}$, \\ Olukiran Olugbenro Emmanueal ${ }^{1}$, Ahmed Rilwan ${ }^{8}$, Joseph Adedayo ${ }^{1}$, Roberts Alero Ann ${ }^{6}$, \\ Oyesegun Razaak ${ }^{8}$, Ketiku Kingsley Kayode ${ }^{7}$, Adenipekun Adeniyi Adesina ${ }^{2}$, \\ Campbell Oladapo Babatunde ${ }^{2}$, Adewuyi Sunday ${ }^{9}$, Chukwuocha Ikechukwu', \\ Otene Samuel Anaja ${ }^{9}$, Duncan Josbert Thomas Kofi ${ }^{7}$, Durosinmi-Etti Francis Abayomi ${ }^{1}$ \\ ${ }^{1}$ Department of Radiotherapy, Lagos University Teaching Hospital, Lagos, Nigeria \\ ${ }^{2}$ Department of Radiotherapy and Oncology, Usmanu Danfodiyo University Teaching Hospital, Sokoto, Nigeria \\ ${ }^{3}$ Department of Radiation Oncology, University College Hospital, Ibadan, Nigeria \\ ${ }^{4}$ Department of Radiation and Clinical Oncology, University of Benin Teaching Hospital, Benin, Nigeria \\ ${ }^{5}$ Department of Radiation Oncology, University of Nigeria Teaching Hospital, Enugu, Nigeria \\ ${ }^{6}$ Department of Community Health, Lagos University Teaching Hospital, Lagos, Nigeria \\ ${ }^{7}$ Department of Radiation Oncology, EKO Hospital, Lagos, Nigeria \\ ${ }^{8}$ Department of Radiotherapy and Oncology, National Hospital, Abuja, Nigeria \\ ${ }^{9}$ Department of Radiotherapy and Oncology, Ahmadu Bello University Teaching Hospital, Zaria, Nigeria
}

Email address:

usmangandi@gmail.com (A. U. Malami)

${ }^{*}$ Corresponding author

\section{To cite this article:}

Salako Omolola, Aliyu Usman Malami, Jimoh Mutiu Alani, Oboh Oseiwe Evaristus, Nwankwo Kenneth, Ogunnorin Babatunde Olutoye, Habeeb Muhammed, Olukiran Olugbenro Emmanueal, Ahmed Rilwan, Joseph Adedayo, Roberts Alero Ann, Oyesegun Razaak, Ketiku Kingsley Kayode, Adenipekun Adeniyi Adesina, Campbell Oladapo Babatunde, Adewuyi Sunday, Chukwuocha Ikechukwu, Otene Samuel Anaja, Duncan Josbert Thomas Kofi, Durosinmi-Etti Francis Abayomi. Techniques and Practice of Post Mastectomy Radiotherapy in Nigeria: A Multi-Centre Study. International Journal of Clinical Oncology and Cancer Research. Vol. 3, No. 3, 2018, pp. 41-48. doi: $10.11648 /$ j.ijcocr.20180303.15

Received: August 10, 2018; Accepted: August 28, 2018; Published: October 8, 2018

\begin{abstract}
Breast cancer affect millions of women worldwide with an increasing incidence in developing countries. In Nigeria, late presentation is the norm, with most patients presenting at stages III and IV. Patients may be at risk of local recurrence after mastectomy due to areas of microscopic residual disease such as the chest wall and regional nodal basins. Post-mastectomy radiotherapy (PMRT) has been found to reduce this risk. The aim of the study was to evaluate the techniques and practice of post mastectomy radiotherapy among breast cancer patients treated in Nigeria. This descriptive retrospective study was carried out for all histologically confirmed breast cancer cases that had post mastectomy radiotherapy between 2004 and 2015, in all (8) centres in Nigeria. Information from patient's records were extracted using data proforma. Data of 2,143 patients were analysed. All patients received radiation to the chest wall. Thirty nine point one percent had two regional nodes irradiated, while $38 \%$ had only axilla treated, and $6.3 \%$ had three regional lymph nodes irradiated. All patients had treatment planning, majority (93.7\%) with conventional technique. The primary beam used was photon with electron boost to the scar (62.8\%). Fractionation method was mostly 50Gy in 25 fractions over 5 weeks $(61.8 \%)$. Three fields were used in treating more than half of the patients $(63.0 \%)$ while $30.9 \%$ were treated with 4 fields' techniques. The study revealed a short fall in access to radiotherapy within the study period. Two dimensional treatment planning method was the dominant with considerable variations across centres in terms of practice and techniques.
\end{abstract}


Keywords: Breast Cancer, Nigeria, Post Mastectomy Radiotherapy

\section{Introduction}

Breast cancer is a disease of global public health concern. It affects millions of women worldwide with an increasing incidence in developing countries. Nigeria continues to experience late stage presentation, with as much as $85 \%$ of patients presenting with stage III and IV disease [1, 2]. Several studies indicate that breast cancer in Nigerian patients is often characteried by unfavourable pathologic and prognostic features, such as large tumour sizes (T3 and T4), unfavourable grades, and greater than four axillary lymphadenopathies [3, 4]. Patients may be at risk of local recurrence after mastectomy due to areas of microscopic residual disease such as the chest wall and regional nodal basins. Post-mastectomy radiotherapy (PMRT) is given in the adjuvant setting to decrease the risk of local recurrence by sterilising micro- or macroscopic malignant cells/residual disease [5].

The management of breast cancer requires a multidisciplinary approach, and every patient's treatment is personalised. Treatment modalities include surgery, chemotherapy, radiotherapy, targeted therapy, and hormonal therapy (anti-oestrogen). Since the inception of breast cancer treatment, mastectomy had been the sole standard treatment to achieve local tumour control. This changed about five decades ago; and with the establishment of adjuvant radiotherapy and chemotherapy, the role of mastectomy as single treatment has declined [6]. In most parts of Nigeria, breast cancer patients receive multimodal treatment with mastectomy being the most popular intervention because of the predominance of locally advanced disease at presentation [7].

One of the first breast cancer clinical trials ever performed commenced in 1949. This early trial clearly demonstrated the benefits of PMRT in which it was noted to reduce local relapse rates by $70 \%$ with no improvements in overall survival rate [8]. Also established was a high and unacceptable rate of cardiac deaths due to unnecessary radiation dose to the heart. This was attributed to the planning techniques employed at that time [9]. A clear outcome was the need to improve on treatment planning techniques and ensure a reduction in radiation exposure to organs at risk such as the heart and lungs. Radiation Oncologists have heeded this call, and necessary modifications to the treatment planning techniques have been adopted. The results of these early clinical trials have changed practice with reduced cardio-toxicity and maximum benefits recorded [10]. As reported in more recent trials, excess cardiac and breast cancer deaths have indeed reduced [11].

Breast cancer radiotherapy management in Nigeria started in Lagos University Teaching Hospital in 1973, with the acquisition of a Cobalt-60 megavoltage machine. Four decades later, there are eight radiotherapy centres with teletherapy machines in Nigeria. Three of these are Cobalt-60 units located in the University College Hospital, Ibadan; Ahmadu Bello University Teaching Hospital, Zaria; and Eko Hospital, Lagos. The five linear accelerators (LINACs) are at the Lagos University Teaching Hospital, Lagos; University of Nigeria Teaching Hospital, Enugu; University of Benin Teaching Hospital, Benin; National Hospital Abuja, Abuja; and Usmanu Danfodio University Teaching Hospital, Sokoto [12]. To date, thousands of breast cancer patients have been irradiated in all these centres with different techniques.

The radiotherapy treatment planning process is complicated and involves the knowledge of the principles of medical physics, radiobiology, radiation safety, dosimetry, simulation and interaction of radiation with other treatment modalities. Each step in the integrated process of radiotherapy needs quality control and assurance to prevent errors, and ensure that patients will receive the prescribed treatment [13]. Hence, radiotherapy needs to be delivered according to approved international guidelines. These techniques involve multiple steps such as delineation of target volumes and organs at risk (such as the lungs and heart), dose-fractionation scheduling, overall treatment time determination, and so on; all of which should be described and performed in a reproducible manner [13].

In Nigeria, some of the deficiencies in the delivery of radiotherapy services includes; inadequate manpower, protracted machine downtime, lack of maintenance contract, lack of central communication between radiotherapy centres, differences in equipment and personnel amongst centres, and the shortage of radiation therapy resources[14]. This survey, which focuses on the practice and techniques of PMRT given in the adjuvant setting, was conducted to determine the techniques in use across Nigerian radiotherapy treatment centres; and provide evidence to guide the development of radiotherapy treatment protocols. This is essential so that interventions such as a standardised breast cancer radiotherapy guideline can be planned to improve the situation.

\section{Material and Methods}

This descriptive retrospective study used patient data between 2004 and 2015, and was carried out in all (8) centres that have megavoltage radiotherapy (linear accelerator and Cobalt-60) machines in Nigeria. The centers are the Lagos University Teaching Hospital (LUTH), Lagos;Eko Hospital (EKO), Lagos; Usman Danfodio University Teaching Hospital (UDUTH), Sokoto; University College Hospital (UCH), Ibadan; National Hospital, Abuja (NHA); University of Nigeria Teaching Hospital (UNTH),Enugu; Ahmadu Bello University Teaching Hospital (ABUTH),Zaria; and University of Benin Teaching Hospital (UBTH), Benin. The study population comprised all histologically confirmed 
cases of breast cancer who received PMRT to the chest wall and nodal regions at these centres. Patients with deficient clinical information from the treatment cards were excluded. A data proforma was jointly developed by the radiotherapy departments of the aforementioned study centres. This comprised of questions on radiotherapy treatment planning, and additional data was obtained from patients' radiotherapy treatment cards. Ethical approval was obtained from the institutions Ethical Review Committees. Analysis was done with Epi Info version 7.2, and results presented in frequencies and percentages.

\section{Results}

The data of 2143 patients were analysed with variable distribution across the eight study centres as presented in Table 1. The largest proportion of patients came from $\mathrm{UCH}$ with $36.6 \%$, followed by LUTH with $14.4 \%$. UDUTH, ABUTH, and NHA had $11.7 \%, 11.1 \%$, and $10.4 \%$ respectively as shown in Table 1 .

Table 1. Patient PMRT distribution across the eight hospitals.

\begin{tabular}{lll}
\hline Hospital & Frequency & Percentage \\
\hline ABUTH & 238 & $11.1 \%$ \\
EKO & 179 & $8.4 \%$ \\
LUTH & 308 & $14.4 \%$ \\
NHA & 224 & $10.4 \%$ \\
UBTH & 97 & $4.5 \%$ \\
UCH & 784 & $36.6 \%$ \\
UDUTH & 250 & $11.7 \%$ \\
UNTH & 63 & $2.9 \%$ \\
Total & 2143 & $100.0 \%$ \\
\hline
\end{tabular}

All patients received radiation to the chest wall with regional node distribution. $39.1 \%$ had two regional nodes (axillary and supraclavicular nodes) irradiated, while 38\% had only axillary nodal are treated, and $6.3 \%$ had three regional lymph nodes (axillary, supraclavicular and parasternal nodes) irradiated. All patients had radiation planning skin marking as presented in Table 2 .

Table 2. Nodal irradiation with skin marks and border point documentation.

\begin{tabular}{lll}
\hline & $\begin{array}{l}\text { Frequency } \\
\text { (n=2143) }\end{array}$ & $\begin{array}{l}\text { Percentage } \\
\text { \% }\end{array}$ \\
\hline Axillary + Supraclavicular nodes & 838 & 39.1 \\
Axillary node only & 815 & 38.0 \\
No node irradiation & 356 & 16.6 \\
Axillary + Supraclavicular + Parasternal nodes & 134 & 6.3 \\
Skin marks & 2143 & 100 \\
\hline
\end{tabular}

A condensed overview of the treatment planning techniques performed across centres, as shown in Table 3, shows that Cobalt-60 machines were used in three centres (treating $56 \%$ of the patients), while five centres used linear accelerators (LINACs) to treat the remaining $44.0 \%$ of patients.
Table 3. Condensed overview of treatment planning techniques.

\begin{tabular}{lll}
\hline & $\begin{array}{l}\text { No of } \\
\text { Radiotherapy } \\
\text { Centres n=8 }\end{array}$ & $\begin{array}{l}\text { Patient } \\
\text { population } \\
\mathbf{n = 2 1 4 3 ( \% )}\end{array}$ \\
\hline $\begin{array}{l}\text { Megavoltage machine type } \\
\text { Linear accelerator 6MV }\end{array}$ & 5 & $942(44)$ \\
Cobalt 60 1.25 MeV & 3 & $1201(56)$ \\
Planning type & & $2008(93.7)$ \\
Conventional 2D planning & 8 & $135(6.3)$ \\
$\begin{array}{l}\text { 3D planning } \\
\text { Beam type }\end{array}$ & 8 & $2143(100.0)$ \\
$\begin{array}{l}\text { Photon beam } \\
\text { Boost modality beam }\end{array}$ & 8 & $302(62.8)$ \\
$\begin{array}{l}\text { Electrons } \\
\text { Photons }\end{array}$ & 3 & $179(37.2)$ \\
$\begin{array}{l}\text { Patient positioning } \\
\text { Supine }\end{array}$ & 3 & $2143(100)$ \\
$\begin{array}{l}\text { Arm abduction } \\
\text { Immobilization device }\end{array}$ & 8 & $2143(100)$ \\
\hline
\end{tabular}

Conventional 2-dimensional planning was used in $93.7 \%$ of cases as against computed tomography (CT), 3dimensional planning which was used in just $6.3 \%$ of cases as depicted in Figure 1.

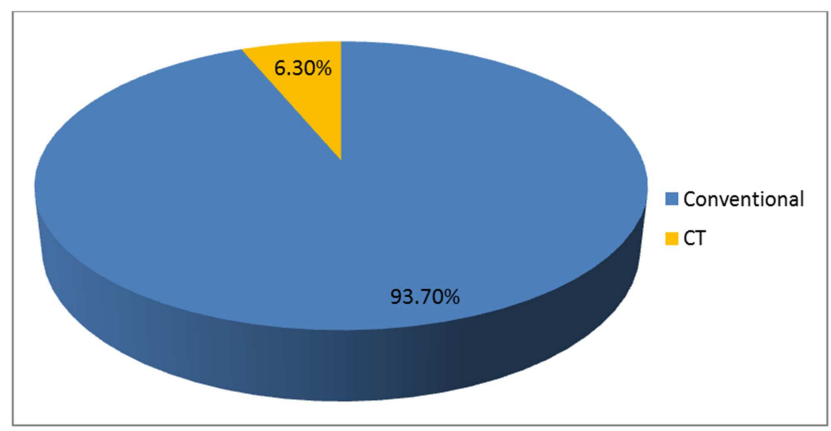

Figure 1. Treatment planning methods.

Table 4 shows the type of fields used in the patients. The most used was the 3-field technique (medial tangential, lateral tangential and Direct Anterior SCF field) in 63\% of the patients, followed by the 4 field technique(medial tangential, lateral tangential, opposing anterior and posterior SCF field) used in $30.9 \%$ of patients.

Table 4. Distribution of radiotherapy fields.

\begin{tabular}{lll}
\hline Field Type & Frequency $(\mathbf{n = 2 1 4 3})$ & Percent \\
\hline Medial tangential & 2143 & $100 \%$ \\
Lateral tangential & 2143 & $100 \%$ \\
Direct Anterior SCF & 1051 & $49.0 \%$ \\
Ant \& posterior SCF & 850 & $39.7 \%$ \\
Parasternal & 450 & $21.0 \%$ \\
\hline
\end{tabular}

Hypofractionation was practised in four centres - EKO Hospital, LUTH, UCH, and UNTH; while conventional fractionation was favoured by ABUTH, NHA, UBTH, and UDUTH. Based on patient proportions, the predominant fractionation regimen used was hypofractionation in $61.78 \%$ while the remaining patients had conventional fractionation regimen as shown in Table 5. 
Table 5. Fractionation regimen.

\begin{tabular}{lll}
\hline Fractionation regimen & Frequency $(\mathbf{n}=\mathbf{2 1 4 3})$ & Percent \\
\hline Conventional fractionation & 819 & $38.2 \%$ \\
Hypofractionation & 1324 & $61.8 \%$ \\
Total & 2143 & $100.0 \%$ \\
\hline
\end{tabular}

The most frequently prescribed dose was $50 \mathrm{~Gy}$ in 25 fractions over 5 weeks, at a rate of 2 Gy per day. This prescription was used across four centers. The remaining centres used $45 \mathrm{~Gy}$ in 18 fractions in 3.5 weeks at $2.5 \mathrm{~Gy}$ per day as shown in Figure 2.

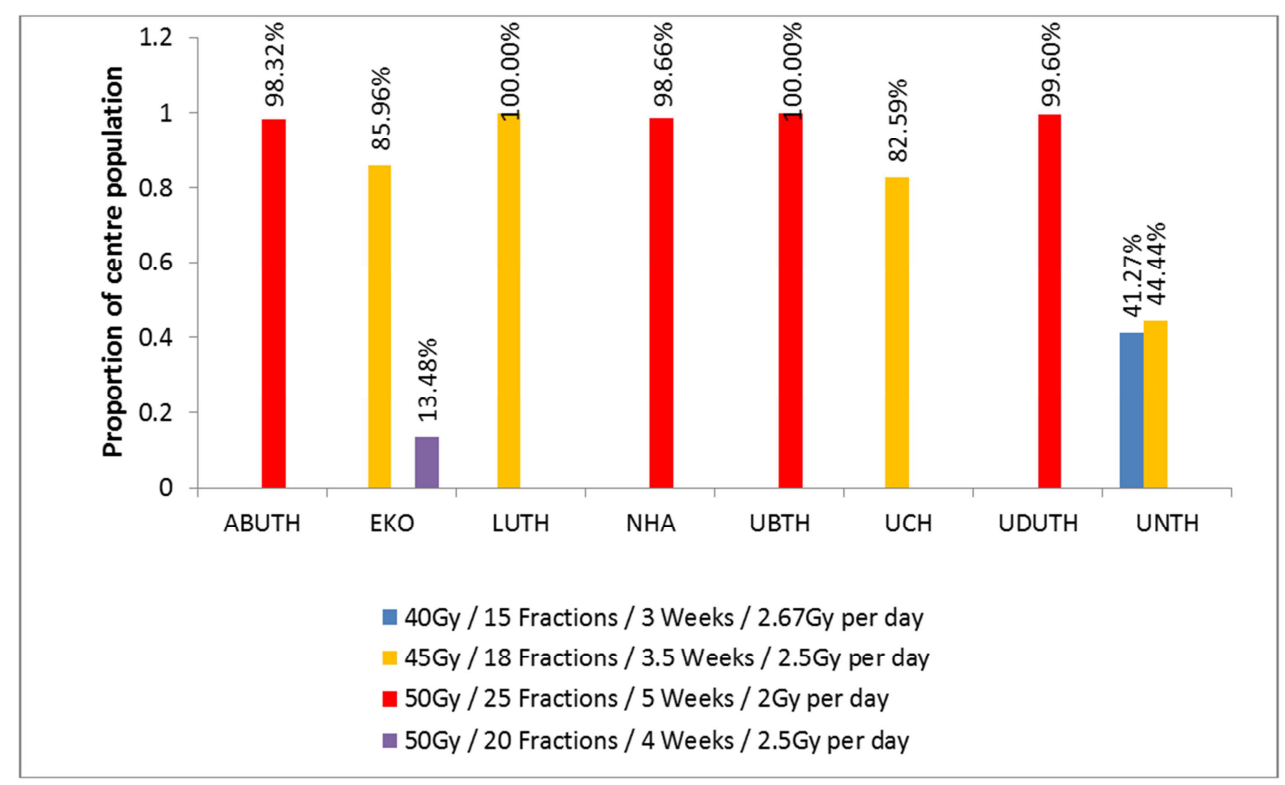

Figure 2. Treatment prescriptions used across centres.

\section{Discussion}

The delivery of radiotherapy involves several steps and various techniques. These are not always in the same order or carried out by the same professionals on a daily basis, and they often include a thorough assessment of the patient, imaging for treatment planning, delineation of target volumes and organs at risk. The treatment plan is then developed and pre-treatment set up, with review and quality control checks carried out by the radiotherapy team comprising the radiation oncologist, therapy radiographer, medical physicist, and others [15].

Nigeria and Egypt bear similarities in the pattern of presentation, with the majority of breast cancer patients presenting with locally advanced disease at diagnosis, and therefore requiring PMRT. However,Egypt has more radiotherapy facilities and better access to radiotherapy [16]. The growth of radiotherapy services in Nigeria has been slow with only eight megavoltage units serving over 155 million Nigerians [17]. This is in contrast to the International Atomic Energy Agency (IAEA) recommendation that there should be one megavoltage equipment per 250,000 population [18]. At the moment, one megavoltage centre serves about 19,000,000 people in Nigeria. This situation is exacerbated by the frequent breakdown of the few megavoltage facilities across the country [19].

Over the study period, 2143 patients received PMRT; a figure lower than expected. The number of irradiated patients is conservatively expected to be half of diagnosed patients. For instance, in 2012, Nigeria recorded an incidence rate of
27,304 new breast cancer cases [20]; yet in the same year, less than $1 \%$ of this reported number received PMRT. A study by Kingham et al pointed out that only $10.8 \%$ of cancer patients received PMRT in Sub-Sahara Africa [21].

The Philippines, which is also a low and middle income country, provided PMRT to about $20 \%$ of breast cancer cases; while in high-income countries such as in North America, access to radiotherapy is about 60\% [22].

Probable reasons for this small proportion of patients with access to PMRT in Nigeria include frequent breakdown of machines, lengthy delays in the repair of machines, with some centres rendered inoperable for between six months and 5 years. Some of the existing megavoltage radiotherapy machines are old and hence reduced operating efficiency. Other reasons may be attributed to low awareness of the benefits of radiotherapy amongst health care professionals, high cost of services in a country where majority pay out of pocket, and poor data recording. This scenario is common across Africa, as there is a global shortfall of radiotherapy services, with more than $90 \%$ of the population in lowincome countries lacking access to radiation services [23]. Nigeria is experiencing a decline in the provision of quality radiotherapy services to the increasing population of cancer patients who require it [12]. However, since Nigeria concluded a successful Democratic Government transition, the Federal Ministry of Health has proposed initiatives to improve existing radiotherapy services and provide seven new radiotherapy machines to different parts of the country [24].

In this study, all patients had PMRT to the chest wall. Ninety three percent of patients received radiation to 
ipsilateral axillary nodes, $80 \%$ to supraclavicular nodes and $21 \%$ to the parasternal nodes. This is similar to an Eastern Cooperative Oncology Group (ECOG) trial where radiation was given to the chest wall as well as the supraclavicular, infraclavicular, axillary, and internal mammary nodes [25]. This study reported a high number of regional node basins which is most likely due to the locally advanced presentations of patients. However, it is important to justify the irradiation of certain fields such as the supraclavicular fossa (SCF). Indications for SCF irradiation include large primary tumour size and positive axillary nodal status. There is a $5 \%$ risk of SCF recurrence if the level I axillary nodes are involved, hence level II and III axillary and SCF nodes may be irradiated [4]. This risk quadruples to $20 \%$ when there is involvement of $\geq 4$ axillary nodes, a single node size $>2 \mathrm{~cm}$, or involvement of level III nodes; all of which make SCF radiotherapy compulsory [4].

When chest wall target volume delineation is performed, various references and landmarks are used. Approximately $7 \%$ of patients were planned with CT planning (Table 3 ). The use of radiopaque wires to mark out the borders and mastectomy scar for those patients who required a boost was frequent in most centres. Also, there was a wide variation in the treatment field borders used in PMRT and boost planning target volume definition. This is possibly due to varying degrees of knowledge and skill sets of radiotherapy team members, as well as the differing capacities of the megavoltage machines in each centre. Treatment field boundaries were documented in the radiotherapy treatment cards with various boundary references and landmarks. Borders used were commonly marked with ink and the most commonly used field reference points were: superiorbordersuprasternal notch; inferior border - xiphisternum or $1.5-3 \mathrm{~cm}$ below the contralateral breast; medial border in the midline or a few centimetres lateral to the midline; lateral border mid-axillary line (MAL) or few centimetres posterior to the MAL.

Historically, PMRT has been delivered with tangential fields for chest wall and separate fields for regional nodes[26]. In this study, the three-field technique (direct anterior supraclavicular, medial, and lateral tangential fields) was the predominant field type used in $63 \%$ of patients. The choice of this field technique may be dependent on ease of setup. The isocentric tangential fields encompassed the chest wall plus or minus the axillary nodes. The third field, a direct anterior supraclavicular field at various depths ranging from 2-3 cm, covers the SCF. Siddon et al [27] used a similar three-field technique but with a different coverage area: two tangential beams and an anterior field that covered the axilla and supraclavicular areas. Benefits of the modified three field method are the simplicity of field set up and the ability to match the field junctions.

The SCF may be treated with two parallel opposed fields, which was received in this study by $30.9 \%$ of patients. This results in a four-field technique comprising of opposing anterior and posterior SCF and medial and lateral tangential fields. [28]. The variation in the choice of direct anterior supraclavicular fossa versus opposing anterior and posterior SCF fields in this study may be attributed to the size and depth of supraclavicular lymphadenopathy and dose distribution across this heterogeneous region.

There are five LINACS and three Cobalt-60 megavoltage machines across the eight centres in Nigeria. In this study, $56 \%$ patients were treated at a Cobalt- 60 center. This is attributable to the fact that the Cobalt- 60 machines were operational in Nigeria many years before the first LINAC was commissioned. Also, the LINACS seem to experience unique challenges and long downtimes due to infrastructural, technical and logistic problems; all of which have been experienced since five LINACs were provided to different centres across Nigeria as part of an upgrade in 2003 [29]. Currently, all the megavoltage machines are operating suboptimally in Nigeria.

The Cobalt-60 is described as being more robust and dependable in developing countries with unstable electricity. In addition to being simpler to operate with the ability to incorporate modern technology such as a multileaf collimator, it is also cheaper to purchase and maintain relative to the LINAC. Although a LINAC poses a lower risk as a radiation hazard, the Cobalt-60 has more dynamic functions and better radiation dosimetry [18]. The IAEA recommends the Cobalt- 60 machine for the delivery of radiotherapy in resource-constrained countries like Nigeria [18].

The utilisation of CT planning is sparse as only two centres in Nigeria practised CT planning during the study period. Only $6.3 \%$ of patients received CT-planned radiotherapy. This is similar to an old Australian survey that reported that only 3 out of 11 Australian institutions used CT treatment planning [30]. The two centres in Nigeria practising CT treatment planning were able to view the geometry of the target volumes, organs at risk, determine the central lung dose (which did not exceed $2 \mathrm{~cm}$ ), and set up patients and beams to receive homogenous doses. The benefits of CT treatment planning have been reported to include better dose precision, dose homogeneity and patient positioning [30]. The ability to conduct 3-dimensional dose calculations and view the geometric positions of the tumor and healthy tissue on a treatment plan are significant advantages that enable the calculation and optimisation of dose [31]. This results in an increased dose to tumour and reduced dose to normal tissue (therapeutic ratio),thereby reducing radiation-induced complications. This study reveals that $2 \mathrm{D}$ planning is the standard planning method used in over $90 \%$ of patients. Two-dimensional planning involves delineation of target volume using anatomical references and a conventional X-ray/fluoroscopic simulator where available.

In this study, photon irradiation (the global standard) was used for all patients. Gaffney et al [32] reported the irradiation of chest wall and internal mammary nodes of 140 patients with electron arc therapy to a total dose of 45-50Gy in 5 to 5.5 weeks. In the study, supraclavicular and axillary nodes were irradiated with two photon fields that were matched.Actuarial 5-year local-regional control (LRC) and 
disease free survival was found to be $91 \%$, and $64 \%$ in the adjuvant group.This substantiates the point that LRC with electron arc therapy of the chest wall is comparable to photon techniques; and with careful attention to treatment planning and dosimetry, electron arc therapy of the chest wall can be safe and efficient [33]. A few other studies have explored the use of high particle beams such as protons. Proton radiation for PMRT is a viable option in a select group of patients. However, it is restricted to clinical trials [33] and facilities for proton therapy are currently not available in Nigeria.

About a quarter of the patients in this study received a boost to the mastectomy scar/chest wall, commonly with electrons $(63 \%)$ while others received photon boost with the use of appropriate bolus material. The benefits of boost radiotherapy have been established in a large randomized trial, which revealed a significant reduction in local recurrence risk upon the addition of a boost to patients with high risk of recurrence [34].

A critical component of radiotherapy techniques is positioning the patient to ensure reproducibility of the treatment from simulation to the end of therapy, as well as limiting geographical miss [4].All patients in this study were treated in the supine position, which is commonly prescribed internationally. Similarly, Jabarri et al [28] indicated that patients are usually placed supine on an angled breast board. The role of the breast board is to modify the sternum and chest wall slope. In this study, 78\% patients were treated and immobilised with a breast board. There is a role for prone position in whole breast radiotherapy in patients with thick or pendulous breasts [35]. Also, all the patients were placed with the ipsilateral or both arms abducted. However, there were variations in arm positioning - with an arm pole, breast board, or arm abducted with palm behind the head. The abduction of the arm lifts the breast superiorly and thus reduces the dose to the heart; whilst also providing reproducibility of the treatment plan.

Hypofractionation regimen employs a large dose per fraction of 2.2 to $4.0 \mathrm{~Gy}$ daily, with a shorter overall treatment period which is usually less than 4 weeks [36]. In this study, $62 \%$ of patients were treated with various hypofractionation regimens; the most common regimen being $45 \mathrm{~Gy}$ in 18 fractions over 3.5 weeks. The daily dose per fraction size ranged from $2.5 \mathrm{~Gy}$ to $3.75 \mathrm{~Gy}$. Also observed was that four centres routinely used hypofractionated regimen while the other four used conventional fractionation prescribed at 50Gy in 25 fractions. Conventional fractionation is defined as the delivery of small doses of $1.2-3 \mathrm{~Gy} /$ fraction on a daily basis over 4-6weeks [37]. One centre practised both fractionation regimens equally. The two centres with the highest number of patients predominantly practised hypofractionation which has a shorter treatment time allowing more patient turnover and access to radiotherapy. This is in contrast to a Zambian study where $75 \%$ of breast and prostate cancer patients were treated with conventional fractionation regimens lasting five weeks [23].

Data from multiple studies showed that hypofractionation and conventional regimens have comparable results in locoregional control and disease-free survival [38]. In the United Kingdom's START-A trial, a dose of 41.6Gy was delivered in 13 fractions over 2.5 weeks in 3.2 daily fractions.A similar Canadian trial employed a regimen of $42.5 \mathrm{~Gy}$ delivered in 16 fractions over 3.5 weeks. Both studies documented excellent local control and toxicity similar to the conventional schedule of 50Gy in 25 fractions given over 5 weeks, a regimen preferred in the United States of America [39, 40].

\section{Conclusion}

This study reveals the shortfall in access to radiotherapy in Nigeria between 2004 and 2015 as less than $10 \%$ of those with the disease had PMRT assuming an incidence of 27,304 breast cancer cases seen in Nigeria in 2012. This national survey also establishes that two-dimensional planning remains the back bone of radiotherapy delivery to breast cancer patients in Nigeria. Majority of patients received regional lymph node irradiation, which reiterates the prevalent locally-advanced pattern of presentation. In addition, this survey reveals considerable variations in post mastectomy radiotherapy techniques across centres in Nigeria which are wholly or partially attributed to the type of Radiotherapy equipment, patient volume and expertise available at each centre.

\section{Recommendations}

On the basis of the findings in this study, it is clear that there is a need to develop a national radiotherapy protocol to ease patient referrals and research; and a federal radiotherapy database registry that records daily practice, techniques, toxicity, outcome and survival of patients receiving radiotherapy. Also, based on the infrastructural challenges being experienced currently, an urgent national radiotherapy task force should be set up to foster a national impact assessment, identify bottlenecks, create sustainable solutions and attract financial and technological investments in radiotherapy services. There is an obvious need to improve the education and research capacity of radiotherapy professionals, while consolidating the role of quality assurance units.

\section{References}

[1] Ntekim A, Nufu FT, Campbell OB. Breast cancer in young women in Ibadan, Nigeria. Afr Health Sci. 2009;9(4):242-246.

[2] Durosinmi-Etti FA. Cancer patients in Nigeria: Causes of delay before diagnosis and treatment. Nig. Qtly. J. Hosp. Med. 1985;3(1):28-30.

[3] Huo D, Ikpatt F, Khramtsov A et al. Population differences in breast cancer: survey in indigenous African women reveals over-representation of triple-negative breast cancer. Journal of Clinical Oncology. 2009;27(27):4515-4521

[4] Barret A, Dobbs J, Morris S, Roques T. Practical Radiotherapy Planning, 4th ed. London: Hodder Arnold; 2009, P. $200-13$. 
[5] Harris S. Radiotherapy for early and advanced breast cancer. Int J Clin Pract. 2001;55:609-612.

[6] Veronesi U, Cascinelli N, Mariani L et al. Twenty-year follow-up of a randomized study comparing breast-conserving surgery with radical mastectomy for early BC. $N$ Engl J Med. 2002;347:1227-32.

[7] Anele A, Bowling M, Eckert G et al. Treatment of breast cancer: Imo State, Nigeria versus Indiana, USA women comparative analytic study. Journal of the West African College of Surgeons. 2014;4(4):39-69.

[8] Paterson R, Russell MH. Breast cancer: evaluation of postoperative radiotherapy. J Fac Radiol. 1959;10:174.

[9] Darby S, McGale P, Correa C, et al. Effect of radiotherapy after breast-conserving surgery on 10-year recurrence and 15 year breast cancer death: meta-analysis of individual patient data for 10,801 women in 17 randomised trials. Lancet. 2011;378:1707-1716.

[10] Cuzick J. Radiotherapy for breast cancer. JNCI J Natl Cancer Inst. 2005;97(6):406-407.

[11] Hojris I, Overgaard M, Christensen JJ et al. Morbidity and mortality of ischaemic heart disease in high-risk breast-cancer patients after adjuvant postmastectomy systemic treatment with or without radiotherapy: analysis of DBCG $82 \mathrm{~b}$ and $82 \mathrm{c}$ randomised trials. Radiotherapy Committee of the Danish Breast Cancer Cooperative Group. Lancet. 1999;354:1.

[12] Irabor OC, Nwankwo KC, Adewuyi SA. The stagnation and decay of radiation oncology resources: lessons from Nigeria. Int. J. Radiat. Oncol. Biol. Phys. 2016;95:1327-1333.

[13] Van der Laan H, Hurkmans CW, Kuten A, et al. Current technological clinical practice in breast radiotherapy; results of a survey in EORTC-Radiation Oncology Group affiliated institutions. Radiotherapy and Oncology. 2010;94(3):280-285.

[14] Adewuyi SA, Campbell OB, Ketiku KK et al. Current status of radiation oncology facilities in Nigeria. West Afr J Radiol. 2013; 20:30-6.

[15] Atun R, Jaffray DA, Barton MB et al. Expanding global access to radiotherapy. The Lancet Oncology. 2015; 16(10):1153-1186.

[16] El Saghir NS, Khalil MK, Eid T et al. Trends in epidemiology and management of breast cancer in developing Arab countries: A literature and registry analysis. Int. J. Surg. 2007; 5(4):225-233.

[17] Nwankwo KC, Dawotola DA, Sharma V. Radiotherapy in Nigeria: Current status and future challenges. West Afr $J$ Radiol. 2013; 20:84-8.

[18] International Atomic Energy Agency. Setting up a Radiotherapy Programme: Clinical, Medical Physics, Radiation Protection and Safety Aspects. Vienna: International Atomic Energy Agency; 2008:6-45.

[19] Ajogwu G. Nigeria Still Lacks Functioning Radiotherapy Machines@56. Daily Times [Internet]. 2016 [cited 25 August 2017]. Available from: http://dailytimes.ng/nigeria-still-lacksfunctioning-radiotherapy-machines-56/.

[20] Ferlay J, Soerjomataram I, Ervik M et al. GLOBOCAN 2012 v1.0, Cancer Incidence and Mortality Worldwide: IARC CancerBase No. 11 [Internet]. Lyon, France: International
Agency for Research on Cancer; 2013. Available from: http://globocan.iarc.fr/old/summary_table_sitehtml.asp? selection $=3152 \&$ title $=$ Breast \&sex $=2 \&$ type $=1 \&$ wind ow $=1 \&$ africa $=1 \&$ sort $=0 \&$ submit $=\% \mathrm{C} 2 \% \mathrm{~A} 0$ Execute $\% \mathrm{C} 2 \% \mathrm{~A}$ 0 , accessed on 25/August/2017.

[21] Kingham TP, Alatise OI, Vanderpuye V et al. Treatment of cancer in sub-Saharan Africa. Lancet Oncol. 2013;14(4):e15867.

[22] Grover S, Xu MJ, Yeager A et al. A Systematic Review of Radiotherapy Capacity in Low- and Middle-Income Countries. Frontiers in Oncology. 2014;4:380.

[23] Zubizarreta EH, Fidarova E, Healy B et al. Need for radiotherapy in low and middle income countries - the silent crisis continues. Clin Oncol (R Coll Radiol). 2015;27(2):107-14.

[24] Ifijeh M. FG to Provide 7 Radiotherapy Machines This Year, Says Adewole. This Day [Internet]. 2016 [cited 20 August 2017]. Available from: http://www.thisdaylive.com/index.php/2016/04/07/fg-toprovide-7-radiotherapy-machines-this-year-says-adewole-2/

[25] Olson JE, Neuberg D, Pandya KJ et al. The role of radiotherapy in the management of operable locally advanced breast carcinoma: results of a randomized trial by the eastern cooperative oncology group. Cancer. 1997;79(6):1138-1149.

[26] Jinli Ma, Jiongyan Li, Jiang Xie. Post mastectomy linac IMRT irradiation of chest wall and regional nodes: dosimetry data and acute toxicities. Radiation Oncology. 2013;8(1):1.

[27] Siddon RL, Buck BA, Harris JR et al.Three-field technique for breast irradiation using tangential field corner blocks. International Journal of Radiation Oncology*Biology*Physics. 1983;9(4):583-588.

[28] Jabbari K, Azarmahd N, Babazade S et al. Optimizing of the tangential technique and supraclavicular fields in 3 dimensional conformal radiation therapy for breast cancer. Journal of Medical Signals and Sensors. 2013;3(2):107-116.

[29] Onwumere O. Government's Role in Cancer Multiplication. Osun Defender [Internet]. 2016 [cited 20 August 2017]. Available from: http://www.osundefender.com/?p=252660.

[30] Veness MJ, Delaney G. Variations in breast tangent radiotherapy: a survey of practice in New South Wales and the Australian Capital Territory. Australas Radiol. 1999;43:334-8.

[31] Pereira GC, Traughber M, Muzic RF, Jr. The role of imaging in radiation therapy planning: Past, present, and future. BioMed Research International. 2014;231090:1-9.

[32] Gaffney DK, Prows J, Leavitt DD et al. Electron arc irradiation of the postmastectomy chest wall: clinical results. Radiotherapy and Oncology. 1997;42(1):17-24.

[33] MacDonald SM, Patel SA, Hickey S et al. Proton therapy for breast cancer after mastectomy: Early outcomes of a prospective clinical trial. International Journal of Radiation Oncology*Biology*Physics. 2013;86(3):484-490.

[34] Bartelink H, Horiot JC, Poortmans PM et al. Impact of a higher radiation dose on local control and survival in breastconserving therapy of early breast cancer: 10-year results of the randomized boost versus no boost EORTC 22881-10882 trial. J Clin Oncol. 2007;25:3259-65.

[35] Rafsanjani Z, Mosleh-Shirazi MA, Faghihi R et al. Breast Cancer and its radiotherapeutic methods. Iranian Journal of Medical Physics. 2012;9(2):75-85. 
[36] Höcht S, Aebersold DM, Albrecht C, et al. Hypofractionated radiotherapy for localized prostate cancer. Strahlentherapie Und Onkologie. 2017;193(1):1-12.

[37] Connell PP, Hellman S. Advances in radiotherapy and implications for the next century: a historical perspective. Cancer Res. 2009;69:383-92.

[38] Plataniotis G. Hypofractionated radiotherapy in the treatment of early breast cancer. World Journal of Radiology. 2010;2(6):197-202.
[39] Bentzen SM, Agrawal RK, Aird EG et al. The UK Standardisation of Breast Radiotherapy (START) Trial A of radiotherapy hypofractionation for treatment of early breast cancer: a randomised trial. Lancet Oncol. 2008;9:331-341.

[40] Whelan T, MacKenzie R, Julian J et al. Randomized trial of breast irradiation schedules after lumpectomy for women with lymph node-negative breast cancer. $J$ Natl Cancer Inst. 2002;94:1143-1150. 